УДК 532.783; 548-14 (C) 2011

\section{ВПЛИВ ОБМЕЖЕНОСТІ СВІТЛОВИХ ПУЧКІВ НА ГІСТЕРЕЗИС ПЕРЕХОДУ ФРЕДЕРІКСА В НЕМАТИЧНІЙ КОМІРЦІ}

\author{
М.Ф. ЛЕДНЕЙ, О.С. ТАРНАВСЬКИЙ
}

Київський національний університет ім. Тараса Шевченка, фізичний факультет (Просп. Академіка Глушкова, 4, Kиїв 03680; e-mail: Ledney@univ. kiev. ua)

\begin{abstract}
Розглянуто вплив форми і обмеженості поперечного розміру падаючого світлового пучка на гістерезис світлоіндукованого переходу Фредерікса в гомеотропно орієнтованій комірці нематичного рідкого кристала. Розглянуто випадки одно- і двовимірно обмежених світлових пучків. Чисельно знайдено значення порогів орієнтаційної нестійкості і стрибків кута відхилення директора при збільшенні і зменшенні інтенсивності падаючого світла залежно від поперечних розмірів світлового пучка. Визначено умови, за яких петля гістерезису стає максимально широкою.
\end{abstract}

\section{1. Вступ}

Підвищена цікавість до явищ переорієнтації директора в комірках нематичних рідких кристалів (НРК) у зовнішніх світлових полях i, зокрема, до його порогової переорієнтації - світлоіндукованого переходу Фредерікса (СПФ) [1,2] пов'язана із широким застосуванням НPK-комірок у різноманітних електроннооптичних пристроях. При цьому важливою характеристикою СПФ є значення порога, при досягненні якого інтенсивністю падаючого на комірку світлового пучка директор НРК із однорідно орієнтованого стану переходить у неоднорідний або навпаки [3-7]. $\mathrm{У}$ роботах $[1,8]$ було показано, що СПФ може також супроводжуватися гістерезисом, тобто величина порога $I_{\text {th }}$ при збільшенні інтенсивності падаючого світла може відрізнятися від величини порога $I_{\mathrm{th}}^{\prime}$ оберненої переорієнтації директора при зменшенні інтенсивності світла. У цьому випадку при досягненні інтенсивністю світла порогових значень директор НРК стрибком переходить із однорідно орієнтованого стану в неоднорідний і навпаки $[8,9]$. Експериментально гістерезис СПФ спостерігали у присутності зовнішніх статичного магнітного [10] і квазістатичного електричного [11] полів. Але до цього часу умови впевненого спостереження гістерезису СПФ залишаються не зовсім ясними.

Як правило, під час розгляду СПФ падаючі на комірку світлові пучки вважаються необмеженими 3 однорідним розподілом інтенсивності. Вплив форми світлового пучка і скінченності його поперечного розміру розглянуто в роботах $[1,2,12]$, однак тільки на величину порога СПФ при збільшенні інтенсивності падаючого світла. У роботі [13] було розглянуто вплив скінченності поперечного розміру світлового пучка і на гістерезис СПФ, проте тільки для одного спеціального випадку одновимірного розподілу інтенсивності.

$\mathrm{У}$ даній роботі розглянуто вплив параметрів скінченних світлових пучків на гістерезис СПФ з метою встановлення оптимальних умов його спостереження на експерименті як у випадку одновимірної, так і двовимірної обмеженості пучка.

\section{2. Рівняння для директора в полі одновимірно обмежених світлових пучків}

Нехай маємо гомеотропно орієнтовану плоскопаралельну комірку НРК, обмежену площинами $z=0$ i $z=L$, з нескінченно жорсткими граничними умовами. На комірку вздовж осі $O z$ нормально падає лінійно-поляризована по осі $O x$ світлова хвиля. Для визначеності будемо вважати падаючий світловий пучок обмеженим по осі $O y$. Оскільки при досягненні порога орієнтаційної нестійкості переорієнтація директора відбувається у площині $x O z$ [2] і система одно- 
рідна в напрямку осі $O x$, то директор в об'ємі комірки будемо шукати у вигляді

$\mathbf{n}=\mathbf{e}_{x} \cdot \sin \varphi(y, z)+\mathbf{e}_{z} \cdot \cos \varphi(y, z)$,

де $\mathbf{e}_{x}, \mathbf{e}_{z}$ - орти декартової системи координат, $\varphi-$ кут відхилення директора від його початкового незбуреного напрямку вздовж осі $O z$.

Розподіл інтенсивності $I(y)$ в поперечному перерізі падаючого світлового пучка подамо у вигляді $I(y)=$ $I_{0} f(y)$, де $I_{0}$ - масштабний множник, а функція $f(y)$ задає форму пучка.

Мінімізуючи вільну енергію комірки НPK за кутом $\varphi$ і враховуючи при цьому в наближенні геометричної оптики розв'язок рівнянь Максвелла для електричного поля падаючої світлової хвилі, отримуємо таке стаціонарне рівняння [13]:

$\left(1-k \sin ^{2} \varphi\right) \frac{\partial^{2} \varphi}{\partial z^{2}}+m \frac{\partial^{2} \varphi}{\partial y^{2}}-k \sin \varphi \cos \varphi\left(\frac{\partial \varphi}{\partial z}\right)^{2}+$

$+\frac{\pi^{2}}{L^{2}} \frac{I_{0}}{I_{\mathrm{Fr}}} \frac{\varepsilon_{\|}^{3 / 2} f(y) \sin \varphi \cos \varphi}{\left(\varepsilon_{\perp}+\varepsilon_{a} \cos ^{2} \varphi\right)^{3 / 2}}=0$,

де $k=\frac{K_{3}-K_{1}}{K_{3}}, m=\frac{K_{2}}{K_{3}}, I_{\mathrm{Fr}}=\frac{8 \pi^{3} \varepsilon_{\|} K_{3}}{\varepsilon_{a} \varepsilon_{\perp} L^{2}}-$ величина порога переходу Фредерікса в полі однорідного необмеженого по ширині світлового пучка при нескінченно жорсткому зчепленні директора 3 поверхнею комірки [1].

Поблизу порога орієнтаційної нестійкості відхилення директора будемо вважати малими. Позначимо $\varphi_{m}$ - максимальний кут відхилення директора, який досягається в середині комірки у центрі світлового пучка, тобто $\varphi_{m}=\varphi(y=0, z=L / 2)$. Очевидно, значення $\varphi_{m}$ залежить від величини $I_{0}$. Зручно розглядати обернену залежність $I_{0}\left(\varphi_{m}\right)$, яка є однозначною і в силу малості кута $\varphi_{m}$ може бути представлена рядом

$I_{0} / I_{\mathrm{Fr}}=\rho+\sigma \varphi_{m}^{2}+\tau \varphi_{m}^{4}+o\left(\varphi_{m}^{4}\right)$

де $\rho, \sigma, \tau$ - невідомі сталі коефіцієнти розкладу, які залежать від вигляду функції $f(y)$. У розкладі (3) враховано, що $I_{0}\left(-\varphi_{m}\right)=I_{0}\left(\varphi_{m}\right)$, оскільки знак кута відхилення $\varphi$ визначається тільки флуктуаціями директора і не залежить від інтенсивності падаючого світла.

Розв'язок рівняння (2) також зручно подати у вигляді розкладу по малому параметру $\varphi_{m}$ :

$\varphi(y, z)=A(y, z) \varphi_{m}+B(y, z) \varphi_{m}^{3}+$
$+C(y, z) \varphi_{m}^{5}+o\left(\varphi_{m}^{5}\right)$,

де $A, B, C$ - невідомі коефіцієнти розкладу. Ряд (4) містить тільки непарні степені $\varphi_{m}$, оскільки знаки кута $\varphi_{m}$ і функції $\varphi\left(\varphi_{m}\right)$ повинні збігатись. Задовольняючи ряд (4) граничні умови нескінченно жорсткого зчеплення директора на поверхнях комірки, отримуEMO

$A(y ; z=0, L)=B(y ; z=0, L)=C(y ; z=0, L)=0$.

Крім того, згідно з означенням максимального кута $\varphi_{m}$ відхилення директора (значення кута $\varphi$ при $y=0$ i $z=L / 2$ ) будемо також мати

$A(y=0, z=L / 2)=1$,

$B(y=0, z=L / 2)=C(y=0, z=L / 2)=0$.

Підставивши розклади (3), (4) у рівняння (2) і прирівнявши до нуля коефіцієнти при відповідних степенях $\varphi_{m}$, отримаємо з точністю до малих членів порядку $\varphi_{m}^{5}$ таку систему лінійних диференціальних рівнянь для функцій $A(y, z), B(y, z)$ і $C(y, z)$ :

$A_{z z}^{\prime \prime}+m A_{y y}^{\prime \prime}+\frac{\pi^{2}}{L^{2}} \rho A f(y)=0$

$B_{z z}^{\prime \prime}+m B_{y y}^{\prime \prime}+\frac{\pi^{2}}{L^{2}} \rho B f(y)=$

$=k A^{2} A_{z z}^{\prime \prime}+k A_{z}^{\prime 2} A-\frac{\pi^{2}}{L^{2}}\left(\rho \alpha A^{3}+\sigma A\right) f(y)$,

$C_{z z}^{\prime \prime}+m C_{y y}^{\prime \prime}+\frac{\pi^{2}}{L^{2}} \rho C f(y)=k A^{2} B_{z z}^{\prime \prime}+2 k A B A_{z z}^{\prime \prime}-$

$-\frac{k}{3} A^{4} A_{z z}^{\prime \prime}+k A_{z}^{\prime 2} B-\frac{2}{3} k A_{z}^{\prime 2} A^{3}+2 k A_{z}^{\prime} B_{z}^{\prime} A-$

$-\frac{\pi^{2}}{L^{2}}\left(3 \rho \alpha A^{2} B+\rho \beta A^{5}+\sigma B+\sigma \alpha A^{3}+\tau A\right) f(y)$.

Тут $\alpha=\frac{3}{2} \frac{\varepsilon_{a}}{\varepsilon_{\|}}-\frac{2}{3}, \beta=\frac{15}{8} \frac{\varepsilon_{a}^{2}}{\varepsilon_{\|}^{2}}-\frac{3}{2} \frac{\varepsilon_{a}}{\varepsilon_{\|}}+\frac{2}{15}$, штрихи в функцій $A, B, C$ позначають частинні похідні по відповідних аргументах.

Вимагаючи, щоб розв'язок отриманої системи рівнянь (7)-(9) задовольняв умови на границях (5) і всередині комірки в центрі світлового пучка (6), знаходимо невідомі коефіцієнти $\rho, \sigma$ і $\tau$ розкладу (3). 


\section{3. СПФ в одновимірно обмежених пучках}

Спочатку проведемо аналіз разкладу (3) не розв'язуючи рівняння (7)-(9). Враховуючи в (3) доданки до членів порядку $\varphi_{m}^{4}$ включно, знаходимо розв'язок отриманого для $\varphi_{m}$ біквадратного рівняння:

$\varphi_{m}^{2}=\left[-\sigma \pm \sqrt{\sigma^{2}+4 \tau\left(I_{0} / I_{\mathrm{Fr}}-\rho\right)}\right] /(2 \tau)$,

де параметри $\rho, \sigma, \tau$ залежать від розподілу інтенсивності в поперечному перерізі падаючого світлового пучка.

Нехай $\sigma>0$, тоді при збільшенні від нуля інтенсивності $I_{0}$ падаючого світла система неперервно переходить із однорідного стану $\left(\varphi_{m}=0\right)$ в неоднорідний $\left(\varphi_{m} \neq 0\right)$ при досягненні порога орієнтаційної нестійкості $I_{\mathrm{th}}=\rho I_{\mathrm{Fr}}$. У системі також відсутній гістерезис, і СПФ є фазовим переходом другого роду. Таку задачу, як зазначалося вище, розглядали в низці робіт [1-7].

Якщо ж параметр $\sigma<0$, то при досягненні порога СПФ $I_{0}=I_{\text {th }}$ система із однорідного стану, згідно 3 рівнянням (10), як і в роботі [8], стрибком переходить в неоднорідний стан з $\varphi_{m}=\sqrt{-\frac{\sigma}{\tau}}$. При оберненому переході, тобто при зменшенні інтенсивності $I_{0}$ iз області значень більших $I_{\mathrm{th}}$ перехід системи у вихідний однорідний стан наявний при менших значеннях інтенсивності $I_{0}=I_{\mathrm{th}}^{\prime}<I_{\mathrm{th}}$. Величину цього порога, як і в [8], знаходимо із умови невід'ємності підкореневого виразу в (10):

$I_{\mathrm{th}}^{\prime}=I_{\mathrm{Fr}}\left(\rho-\frac{\sigma^{2}}{4 \tau}\right)=I_{\mathrm{th}}-\Delta I_{\mathrm{th}}$,

$\Delta I_{\mathrm{th}}=I_{\mathrm{Fr}} \frac{\sigma^{2}}{4 \tau}>0$

$\mathrm{y}$ цьому випадку при досягненні $I_{0}=I_{\mathrm{th}}^{\prime}$ система стрибком повертається у вихідний однорідний стан із неоднорідного стану з $\varphi_{m}=\sqrt{-\frac{\sigma}{2 \tau}}$. Як видно, в системі присутній гістерезис, а СПФ при цьому є фазовим переходом першого роду.

Нехай розподіл інтенсивності в поперечному перерізі падаючого світлового пучка описується функцією $I(y)=I_{0} \operatorname{ch}^{-2}(y / a)$. Обмежений при $y \rightarrow \pm \infty$ розв'язок рівняння (7), що задовольняє умови $(5),(6)$, набуває вигляду [15]:

$A(y, z)=\operatorname{ch}^{-\varepsilon} \frac{y}{a} \sin \frac{\pi z}{L}$, де $\varepsilon=\frac{\pi a}{\sqrt{m} L}$. Величина обезрозміреного порога СПФ при зростаючій інтенсивності світла визначається коефіцієнтом $\rho$ у розкладі (3) і дорівнює

$\frac{I_{\mathrm{th}}}{I_{\mathrm{Fr}}}=\rho=1+\frac{\sqrt{m} L}{\pi a}$.

Розв'язки рівнянь (8), (9) та отримані при цьому значення параметрів $\sigma$ (Д1.5) і $\tau$ (Д1.6) наведено в Додатку.

Наведені на рис. 1,a розрахункові залежності обезрозмірених величин порога СПФ при зростаючій $I_{\mathrm{th}} / I_{\mathrm{Fr}}($ крива 1$)$ і спадаючій $I_{\mathrm{th}}^{\prime} / I_{\mathrm{Fr}}$ (крива 2) інтенсивності падаючого світла від ширини світлового пучка мають якісно такий самий характер, як і для пучка з $I(y)=I_{0} \Theta(a-|y|)$, розглянутого нами раніше в роботі [13]. Однак у даному випадку розподілу інтенсивності в пучку, як видно з рис. 1,б, зі зростанням відношення $a / L$ ширина петлі гістерезису монотонно зростає від нуля для вузьких пучків до деякого сталого значення для широких $(a / L \gtrsim 20)$ пучків. Максимальна ширина петлі гістерезису виявляється приблизно такою ж, як і для пучків з $I(y)=$ $I_{0} \Theta(a-|y|)$ [13]. При чисельних розрахунках використані значення параметрів НPK $k=0,6, m=0,3$, $\varepsilon_{\|}=3,06, \varepsilon_{\perp}=2,37$ близькі до типових [14].

Як видно з рис. 2 , значення стрибків $\Delta \varphi_{m}$ максимального кута відхилення директора монотонно зростають зі зростанням поперечного розміру $a / L$ пучка i виходять на насичення при $a / L \gtrsim 10$, якісно повторюючи аналогічну залежність ширини петлі гістерезису. Максимальні значення стрибків $\Delta \varphi_{m}$ виявляються практично такими ж, як і для пучка з $I(y)=I_{0} \Theta(a-|y|)[13]$.

Як показують розрахунки, область існування гістерезису СПФ визначається значеннями параметрів $k$ i $m$. Для кожного значення відношення $a / L$ i параметра $m$ існує критичне значення параметра $k_{\mathrm{th}}=$ $-6 \alpha \rho \varepsilon /(4 \varepsilon+1)$, яке визначається рівнянням $\sigma=0$, так, що при $k<k_{\text {th }}$ має місце СПФ без гістерезису $(\sigma>0)$, а при $k_{\mathrm{th}}<k<1-\mathrm{CП \Phi} \mathrm{супроводжується}$ гістерезисом $(\sigma<0)$. Наведені на рис. 3 залежності критичного значення $k_{\mathrm{th}}(a / L)$ i $k_{\mathrm{th}}(m)$ побудовані для декількох значень параметрів $m$ і $a / L$, відповідно, мають якісно такий же характер, як і для пучка 3 $I(y)=I_{0} \Theta(a-|y|)[13]$. Для всіх $m$ при збільшенні відношення $a / L$ критичне значення $k_{\mathrm{th}}$ монотонно спадає, наближаючись у граничному випадку необмежено широкого $(a / L \rightarrow \infty)$ пучка до деякого скінченного значення $k_{\mathrm{th}}^{\infty}=1-\frac{9}{4} \frac{\varepsilon_{a}}{\varepsilon_{\|}}$, яке не залежить від форми 


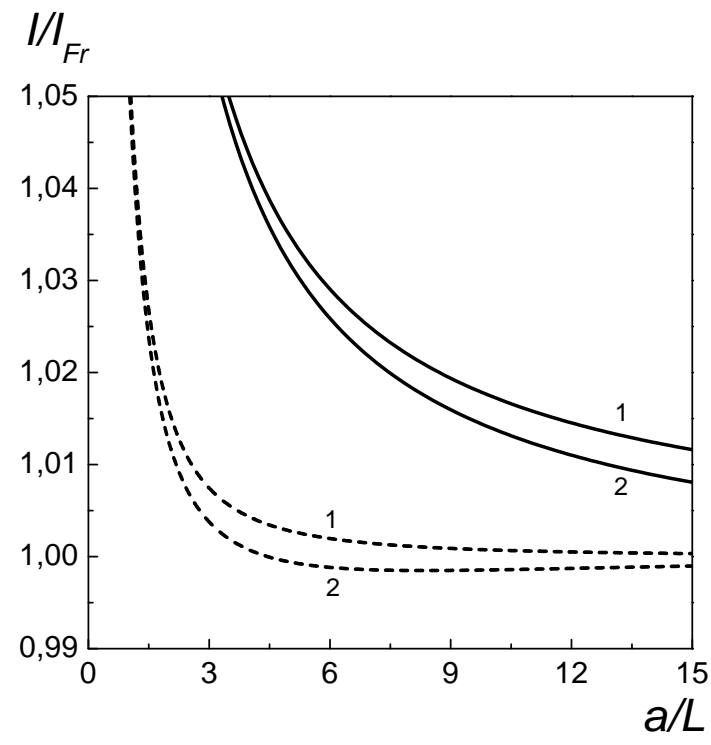

$a$

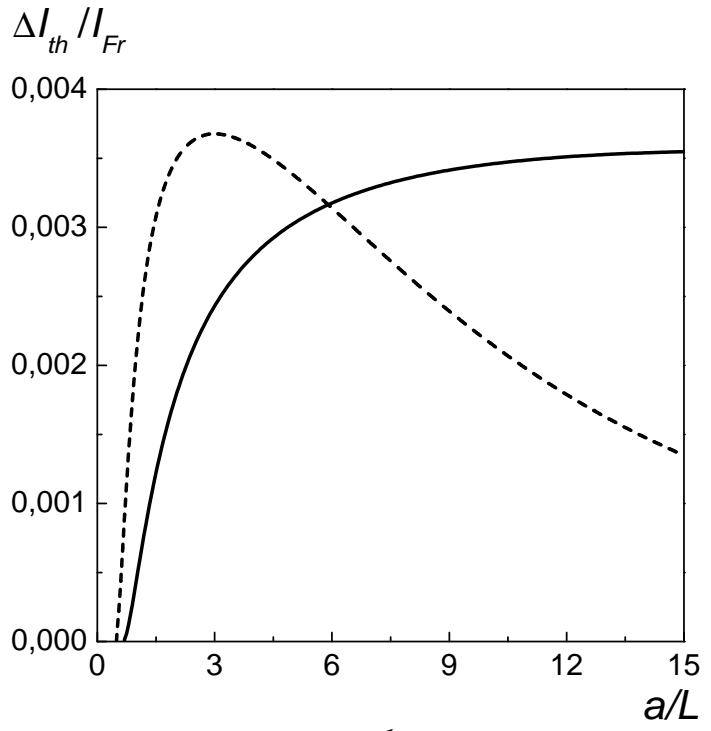

$\sigma$

Рис. 1. Залежності значень порога СПФ $I_{\mathrm{th}} / I_{\mathrm{Fr}}(a)$ при зростаючій (1), спадаючій (2) інтенсивності та ширини петлі гістерезису $\Delta I_{\mathrm{th}} / I_{\mathrm{Fr}}(б)$ від величини відношення $a / L$ для падаючого світлового пучка $3 I(y)=I_{0} \mathrm{ch}^{-2}(y / a)($ суцільні лініі) і $I(y)=I_{0} \Theta(a-|y|)$ (штрихові лініі); $k=0,6, m=0,3, \varepsilon_{a} / \varepsilon_{\|}=0,22$

одновимірно обмеженого світлового пучка. Зауважимо, що при значеннях параметра $k<k_{\text {th }}^{\infty}$, незалежно від величини $m$, СПФ проходить без гістерезису в пучках довільної ширини. Як видно з рисунка, зменшення відношення $a / L$ і збільшення $m$ приводять до звуження по параметру $k$ області існування гістерезису СПФ.

На рис. 4 наведено залежності критичного значення параметра $m_{\mathrm{th}}=(\pi a / L)^{2}(4+6 \alpha \rho / k)^{2}$ (значення $m$, які відповідають $\sigma=0)$ залежно від величини відношення $a / L$ для декількох значень $k$. Тут область $0<$ $m<m_{\text {th }}$ є областю СПФ, який супроводжується гістерезисом. Якщо $m>m_{\mathrm{th}}$, то СПФ проходить без гістерезису. Як видно з рисунка, зменшення відношення $a / L$ i величини параметра $k$ (де $k_{\mathrm{th}}<k<1$ ) приводить до звуження по параметру $m$ області існування гістерезису СПФ.

Як випливає з рис. 3, 4, області існування гістерезису СПФ по параметрах $k$ і $m$ слабо залежать від форми одновимірно обмеженого світлового пучка.

\section{4. СПФ у двовимірно обмежених пучках}

Нехай розподіл інтенсивності світла в поперечному перерізі падаючого пучка обмежений по обох координатах $x$ і $y$ та для визначеності має вигляд $I(r)=$ $I_{0} \Theta(R-r)$, де $R$ - радіус пучка, $r$ - відстань до осі пучка. Для пружних сталих Франка використовуємо

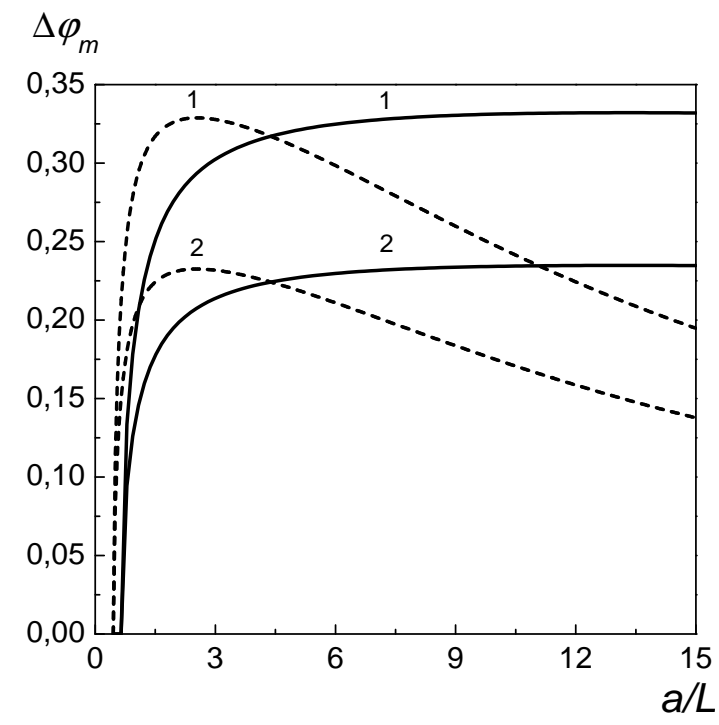

Рис. 2. Величини стрибків $\Delta \varphi_{m}$ максимального кута відхилення директора при зростаючій (1) і спадаючій (2) інтенсивності як функції $a / L$ для світлового пучка з $I(y)=I_{0} \mathrm{ch}^{-2}(y / a)$ (суцільні лініі) і $I(y)=I_{0} \Theta(a-|y|)$ (штрихові лініі); $k=0,6$, $m=0,3, \varepsilon_{a} / \varepsilon_{\|}=0,22$

одноконстантне наближення $K_{1}=K_{2}=K_{3}=K$, оскільки в цьому випадку деформації директора залишаються плоскими $[1,2] .3$ урахуванням розв'язку рівнянь Максвелла стаціонарне рівняння для директора отримуємо аналогічне рівнянню (2), в яко- 

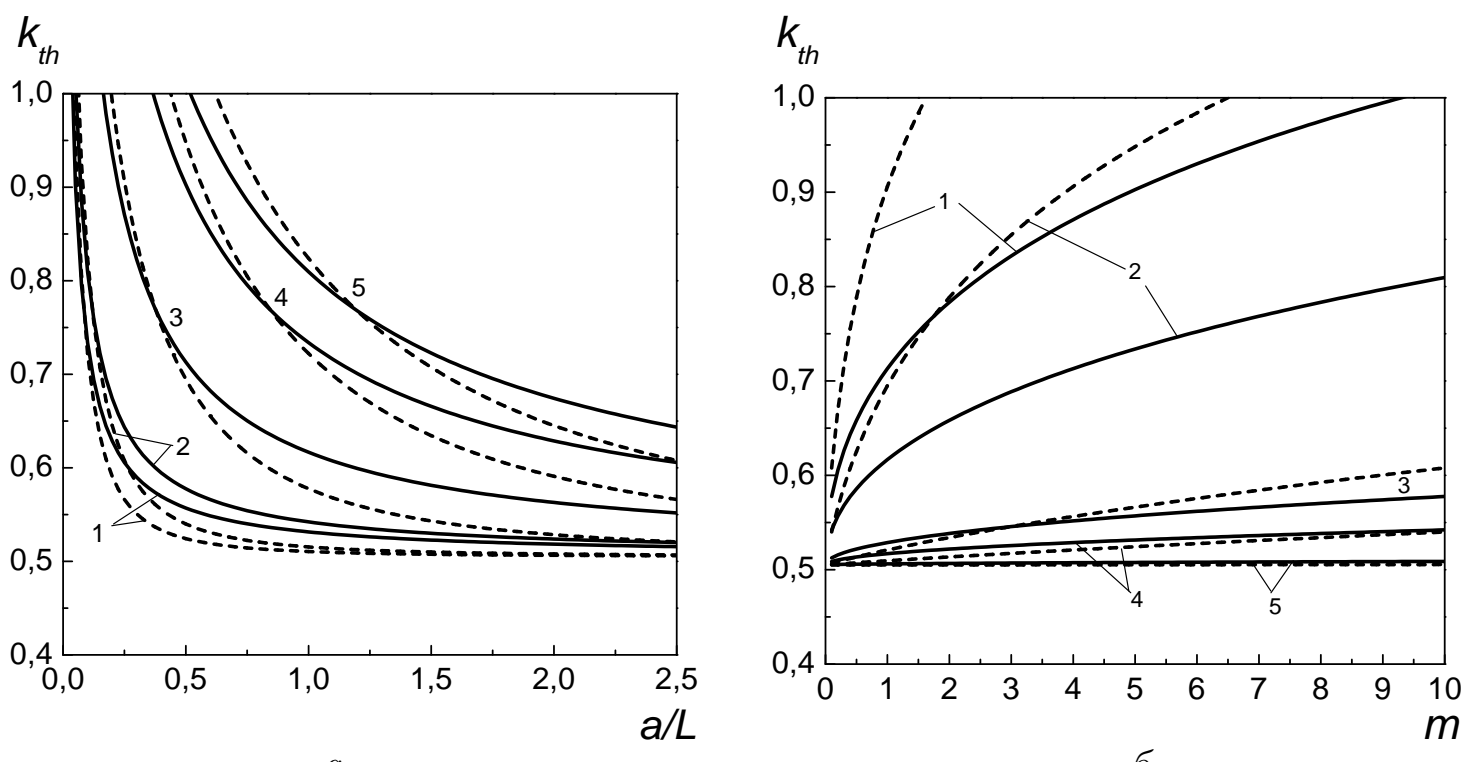

$a$

6

Рис. 3. Залежності критичних значень параметра $k_{\mathrm{th}}: k_{\mathrm{th}}(a / L)$ при $m=0,05(1), 0,1$ (2), $1(3), 5(4), 10(5)(a)$ i $k_{\mathrm{th}}(m)$ при $a / L=0,5(1), 1(2), 5(3), 10(4), 100(5)$ для світла інтенсивності $I(y)=I_{0} \operatorname{ch}^{-2}(y / a)$ (суцільні лінії) і $I(y)=I_{0} \Theta(a-|y|)$ (штрихові лініі) (б)

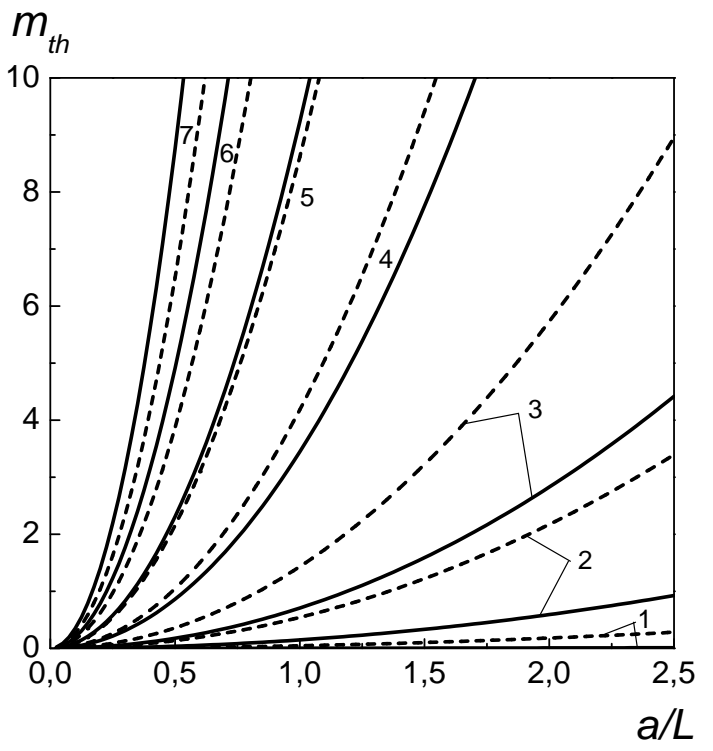

Рис. 4. Залежність критичного значення параметра $m_{\text {th }}$ від величини відношення $a / L$ для розподілів інтенсивності світла $I(y)=I_{0} \operatorname{ch}^{-2}(y / a)$ (суцільні лінії) і $I(y)=I_{0} \Theta(a-|y|)$ (штрихові лінії); $k=0,51$ (1), 0,55 (2), 0,6 (3), 0,7 (4), 0,8 (5), $0,9(6), 0,99(7)$

му $k=0, m=1$, а кут $\varphi$ відхилення директора залежить від $r$ і $z$. Підставивши розклади (3) і (4) у рівняння для директора, отримаємо аналогічну (7)-(9) (з тією різницею, що тепер оператор Лапласа представляється в циліндричних координатах $r$ і $z$ ) си- стему диференціальних рівнянь відносно невідомих функцій $A(r, z), B(r, z)$ і $C(r, z)$.

Згідно $з$ рівнянням (7), функція $A(r, z)$, що задовольняє умови (5), (6), обмежена при $r \rightarrow \infty$ і неперервна разом зі своєю першою похідною на межі пучка $r=R$, має вигляд

$A(r, z)= \begin{cases}J_{0}(q r) \sin \frac{\pi z}{L}, & \text { якщо } r \leqslant R, \\ \frac{J_{0}(q R)}{K_{0}(\tilde{q} R)} K_{0}(\tilde{q} r) \sin \frac{\pi z}{L}, & \text { якщо } r>R,\end{cases}$

де $q=\tilde{q} \sqrt{\rho-1}, \tilde{q}=\pi / L, J_{n}(x), K_{n}(x)$ - відповідно, звичайна і модифікована функції Бесселя. Параметр $\rho$, що визначає величину порога СПФ $I_{\mathrm{th}}$ при зростаючій інтенсивності - перший нетривіальний корінь рівняння

$$
\frac{q J_{1}(q R)}{J_{0}(q R)}=\frac{\tilde{q} K_{1}(\tilde{q} R)}{K_{0}(\tilde{q} R)} .
$$

Розв'язавши рівняння (8) і (9), знайдемо значення параметрів

$\sigma=-\frac{3}{2} \frac{\alpha \rho}{J_{0}^{2}(q R)+J_{1}^{2}(q R)} \int_{0}^{1} J_{0}^{4}(q R t) t d t$

i $\tau$, вираз для якого не наведено, оскільки він громіздкий. 


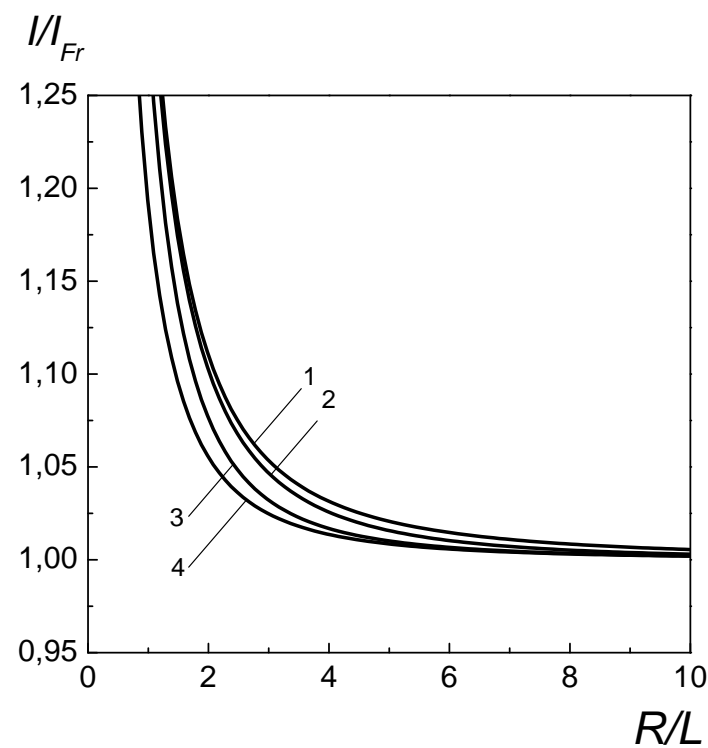

$a$
$\Delta l_{t h} / I_{F r}$

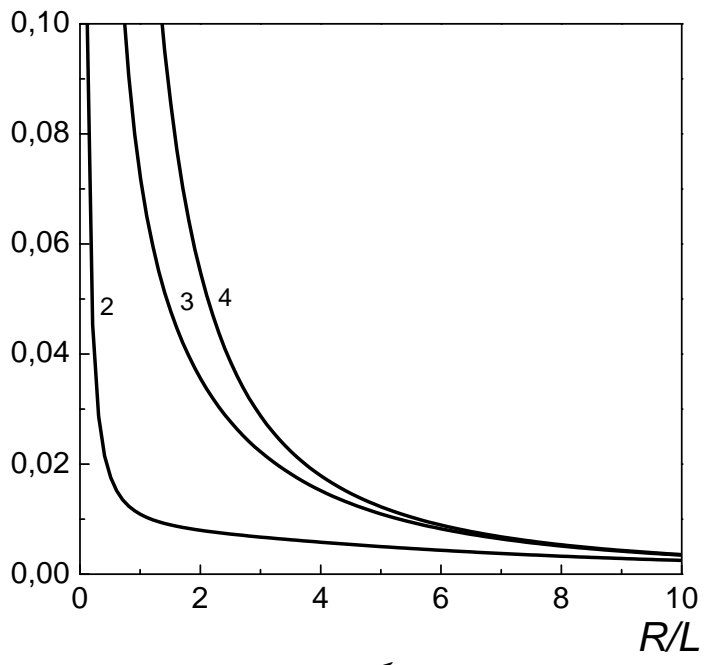

б

Рис. 5. Значення порога СПФ $I_{\mathrm{th}} / I_{\mathrm{Fr}}(a)$ при зростаючій $(1)$, спадаючій (2, 3, 4) інтенсивності та ширина петлі гістерезису $\Delta I_{\mathrm{th}} / I_{\mathrm{Fr}}(б)$ як функції поперечного розміру $R / L$ двовимірно обмеженого світлового пучка з $I(r)=I_{0} \Theta(R-r) ; \varepsilon_{a} / \varepsilon_{\|}=0,5$ (2), $0,6(3), 0,9(4)$

На рис. 5, а наведено результати чисельного розрахунку величин порога СПФ при зростаючій $I_{\mathrm{th}} \mathrm{i}$ спадаючій $I_{\mathrm{th}}^{\prime}$ інтенсивності від поперечного розміру світлового пучка, отримані для декількох значень відношення $\varepsilon_{a} / \varepsilon_{\|}$. Як видно із рис. 5, 6 , на відміну від одновимірно обмежених світлових пучків, із зростанням поперечного розміру пучка ширина петлі гістерезису монотонно спадає від необмежено великого значення для нескінченно вузьких пучків до нуля для необмежено широких пучків. Зі зростанням відношення $\varepsilon_{a} / \varepsilon_{\|}$ширина петлі гістерезису монотонно зростає.

Наведені на рис. 6 залежності величин стрибків $\Delta \varphi_{m}$ максимального кута відхилення директора від поперечного розміру світлового пучка $є$ немонотонними: зі зростанням $R / L$ величина $\Delta \varphi_{m}$ спочатку збільшується до деякого максимального значення, а потім монотонно спадає до нуля в граничному випадку $R / L \rightarrow \infty$. На відміну від одновимірно обмежених світлових пучків залежності величини стрибків $\Delta \varphi_{m}$ і ширини $\Delta I_{\mathrm{th}}$ петлі гістерезису від поперечного розміру світлового пучка якісно різні.

Зауважимо, що для двовимірно обмежених пучків СПФ супроводжується гістерезисом у комірках НРК з $\frac{\varepsilon_{a}}{\varepsilon_{\|}}>\frac{4}{9}$, як і у випадку однорідного необмеженого по ширині світлового пучка [8].

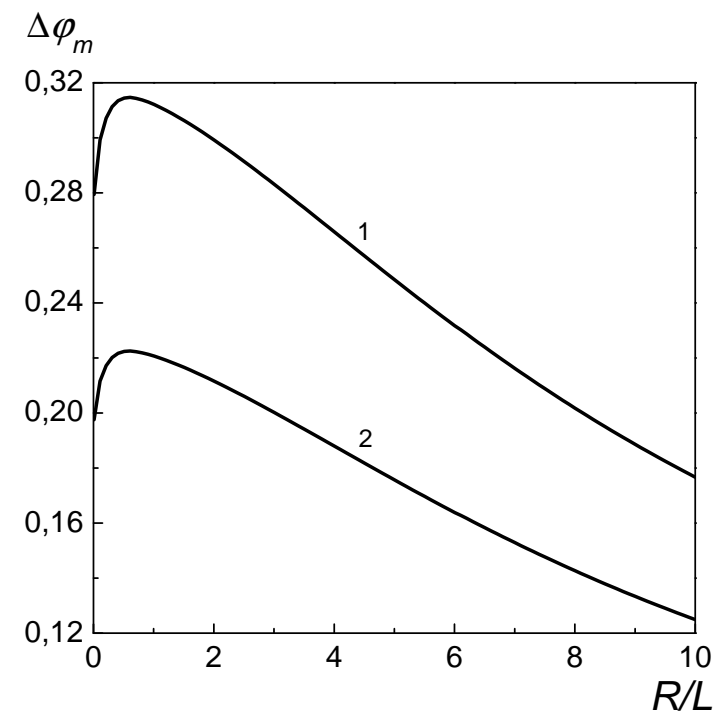

Рис. 6. Залежність величини стрибків $\Delta \varphi_{m}$ максимального кута відхилення директора при зростаючій (1) і спадаючій (2) інтенсивності від величини відношення $R / L$ двовимірно обмеженого світлового пучка при $\varepsilon_{a} / \varepsilon_{\|}=0,5$

Таким чином, форма падаючого світлового пучка i скінченність його поперечного розміру впливають не тільки на величини порогів СПФ, але і на умови впевненого спостереження гістерезису. Область існування гістерезису СПФ звужується по величинах параметрів $k$ i $m$ зі зменшенням ширини одновимір- 
но обмеженого світлового пучка і практично не залежить від вигляду функції розподілу інтенсивності в ньому. Форма одновимірно обмеженого світлового пучка суттєво впливає на значення порогів і ширину петлі гістерезису. Як показують розрахунки, залежність ширини петлі гістерезису від поперечного розміру пучка може бути як немонотонною (для пучка з $\left.I(y)=I_{0} \Theta(a-|y|)\right)$, так і монотонною (для пучка з $\left.I(y)=I_{0} \operatorname{ch}^{-2}(y / a)\right)$. При цьому максимальна ширина петлі гістерезису для пучка з $I(y)=I_{0} \Theta(a-|y|)$ досягається при $a / L \approx 3$ і по величині виявляється практично такою, як і для пучка з $I(y)=I_{0} \operatorname{ch}^{-2}(y / a)$ при $a / L \gtrsim 20$. Залежності стрибків максимального кута відхилення директора від поперечного розміру одновимірно обмеженого світлового пучка якісно повторюють залежність ширини петлі гістерезису, а їх максимальні значення практично не залежать від форми пучка.

У двовимірно обмежених пучках ширина петлі гістерезису СПФ набуває найбільшого значення для нескінченно вузького пучка і монотонно спадає до нуля зі зростанням його поперечного розміру.

Незалежно від форми пучка і його обмеженості ширина петлі гістерезису зростає зі збільшенням анізотропії нематичного рідкого кристала.

Автори висловлюють щиру подяку І.П. Пінкевичу за корисні зауваження при обговоренні результатів роботи.

\section{ДОДАТОК}

Підставивши в рівняння (8) (враховуючи явний вигляд функцій $f(y)=\operatorname{ch}^{-2}(y / a)$ і $\left.A(y, z)(12)\right)$ розв'язок для $B(y, z)$ у вигляді

$B(y, z)=b_{1}(y) \sin \frac{\pi z}{L}+b_{3}(y) \sin \frac{3 \pi z}{L}$,

отримаємо два незалежних диференціальних рівняння для знаходження невідомих функцій $b_{1}(y)$ і $b_{3}(y)$. Ввівши змінну $\xi=\operatorname{th}(y / a)$ і зробивши підстановку $b_{n}(\xi)=(1-$ $\left.\xi^{2}\right)^{n \varepsilon / 2} \omega_{n}(\xi),(n=1,3)$, перепишемо їх у такому вигляді:

$\hat{L}_{1} \omega_{1}(\xi)=-\frac{\varepsilon^{2}}{4}\left[2 k\left(1-\xi^{2}\right)^{\varepsilon-1}+3 \alpha \rho\left(1-\xi^{2}\right)^{\varepsilon}+4 \sigma\right]$,

$\hat{L}_{3} \omega_{3}(\xi)-2 \varepsilon(4 \varepsilon+1) \omega_{3}(\xi)=\frac{\varepsilon^{2}}{4}\left[2 k\left(1-\xi^{2}\right)^{-1}+\alpha \rho\right]$,

де

$\hat{L}_{n}=\left(1-\xi^{2}\right) \frac{d^{2}}{d \xi^{2}}-2(n \varepsilon+1) \xi \frac{d}{d \xi}$.

Обмежений при $\xi= \pm 1(y \rightarrow \pm \infty)$ розв'язок рівнянь (Д1.2) i (Д1.3) шукаємо у вигляді розкладу по власних функціях операторів $\hat{L}_{n}$, а саме:

$\omega_{1}(\xi)=\sum_{m=0}^{\infty} C_{m} P_{m}^{(\varepsilon, \varepsilon)}(\xi), \quad \omega_{3}(\xi)=\sum_{m=0}^{\infty} D_{m} P_{m}^{(3 \varepsilon, 3 \varepsilon)}(\xi)$, де

$\hat{L}_{n} P_{m}^{(n \varepsilon, n \varepsilon)}(\xi)=-m(m+2 n \varepsilon+1) P_{m}^{(n \varepsilon, n \varepsilon)}(\xi), \quad n=1,3$.

Тут $P_{m}^{(n \varepsilon, n \varepsilon)}$ - поліноми Якобі, $C_{m}, D_{m}$ - невідомі коефіцієнти розкладу.

Підставивши розклади (Д1.4) у рівняння (Д1.2), (Д1.3), використавши ортогональність поліномів Якобі і звернувши увагу на умову (6) для функції $B(y, z)$, знаходимо невідомі коефіцієнти $C_{m}, D_{m}$ та значення параметра $\sigma$ у вигляді

$\sigma=-\frac{2^{2 \varepsilon-2} \Gamma(2 \varepsilon+2) \Gamma^{2}(2 \varepsilon)}{\Gamma^{2}(\varepsilon+1) \Gamma(4 \varepsilon)}\left[\frac{k}{2}+\frac{3 \alpha \rho \varepsilon}{4 \varepsilon+1}\right]$,

де $\Gamma(x)$ - гамма-функція.

Аналогічно шукаючи розв'язок рівняння (9) з урахуванням явного вигляду функцій $A(y, z)$ і $B(y, z)$, отримаємо значення параметра $\tau$ :

$\tau=\frac{\Gamma(2 \varepsilon+2)}{2^{2 \varepsilon+3} \Gamma^{2}(\varepsilon+1)}\left[\sum_{m=0}^{\infty}\left(6 k D_{m} w_{m}-6 k C_{m} v_{m}-\right.\right.$

$\left.-9 \alpha \rho C_{m} u_{m}\right)+k \frac{2^{6 \varepsilon-2} \Gamma^{2}(3 \varepsilon)}{\Gamma(6 \varepsilon)}-5 \beta \rho \frac{2^{6 \varepsilon} \Gamma^{2}(3 \varepsilon+1)}{\Gamma(6 \varepsilon+2)}-$

$-3 \alpha \sigma \frac{2^{4 \varepsilon+1} \Gamma^{2}(2 \varepsilon+1)}{\Gamma(4 \varepsilon+2)}+3 \alpha \rho D_{0} \frac{2^{6 \varepsilon+1} \Gamma^{2}(3 \varepsilon+1)}{\Gamma(6 \varepsilon+2)}-$

$\left.-\sigma C_{0} \frac{2^{2 \varepsilon+3} \Gamma^{2}(\varepsilon+1)}{\Gamma(2 \varepsilon+2)}\right]$,

де

$u_{m}=\int_{-1}^{1}\left(1-x^{2}\right)^{2 \varepsilon} P_{m}^{(\varepsilon, \varepsilon)}(x) d x$,

$v_{m}=\int_{-1}^{1}\left(1-x^{2}\right)^{2 \varepsilon-1} P_{m}^{(\varepsilon, \varepsilon)}(x) d x$,

$w_{m}=\int_{-1}^{1}\left(1-x^{2}\right)^{3 \varepsilon-1} P_{m}^{(3 \varepsilon, 3 \varepsilon)}(x) d x$.

1. Б.Я. Зельдович, Н.В. Табирян, Ю.С. Чилингарян, ЖЭТФ 81, №1(7) 72 (1981).

2. Б.Я. Зельдович, Н.В. Табирян, ЖЭТФ 82, №4 1126 (1982).

3. М.И. Барник, А.С. Золотько, В.Г. Румянцев, Д.Б. Терсков, Кристаллография 40, 746 (1995).

4. М.Ф. Ледней, И.П. Пинкевич, В.Ю. Решетняк, ЖЭТФ 107, №6 1921 (1995).

5. М.Ф. Ледней, И.П. Пинкевич, Кристаллография $\mathbf{4 3}$, №4 723 (1998).

6. M. Ledney and I. Pinkevich, Mol. Cryst. Liq. Cryst. 367, 219 (2001).

7. М.Ф. Ледней, Письма в ЖКЭТФ 85, №7 407 (2007).

8. H.L. Ong, Phys. Rev. A 28, 2393 (1983).

9. H.L. Ong, Phys. Rev. A 31, 3450 (1985). 
10. A.J. Karn, S.M. Arakelian, Y.R. Shen, and H.L. Ong, Phys. Rev. Lett. 57, 448 (1986).

11. Chen Shu-Hsia and J.J. Wu, Appl. Phys. Lett. 52, 1998 (1988).

12. A.A. Berezovskaya, S.N. Yezhov, M. Ledney, and I. Pinkevich, Funct. Mater. 14, 510 (2007).

13. М.Ф. Ледней, А.С. Тарнавский, Кристаллография $\mathbf{5 5}$, 337 (2010).

14. Л.М. Блинов, Электро- и магнитооптика жидких кристаллов (Наука, Москва, 1978).

15. Л.Д. Ландау, Е.М. Лифшиц, Квантовая механика. Нерелятивистская теория (Наука, Москва, 1974).

Одержано 27.05.10

\section{ВЛИЯНИЕ ОГРАНИЧЕННОСТИ СВЕТОВЫХ ПУЧКОВ НА ГИСТЕРЕЗИС ПЕРЕХОДА ФРЕДЕРИКСА В НЕМАТИЧЕСКОЙ ЯЧЕЙКЕ}

М.Ф. Ледней, А.С. Тарнавский

$\mathrm{P}$ е $з$ ю м е

Рассмотрено влияние формы и ограниченности поперечного размера падающего светового пучка на гистерезис светоиндуцированного перехода Фредерикса в гомеотропно ориентированной ячейке нематического жидкого кристалла. Рассмотрены случаи одно- и двумерно ограниченных световых пучков.
Численно найдены значения порогов ориентационной неустойчивости и скачки угла отклонения директора при увеличении и уменьшении интенсивности падающего света в зависимости от поперечных размеров светового пучка. Определены условия, при которых петля гистерезиса становится максимально широкой.

INFLUENCE OF LIGHT-BEAM CONFINEMENT

ON THE HYSTERESIS AT THE FRIEDERICKSZ

TRANSITION IN A NEMATIC LIQUID CRYSTAL CELL

M.F. Ledney, O.S. Tarnavskyy

Physics Faculty, Taras Shevchenko National University of Kyiv (4, Prosp. Academician Glushkov, Kyiv 03680, Ukraine; e-mail: Ledney@univ.kiev.ua)

$\mathrm{S} \mathrm{u} \mathrm{m} \mathrm{m} \mathrm{a} \mathrm{r} \mathrm{y}$

The influence of the shape and the finite transverse size of an incident light beam on the hysteresis at the light-induced Friedericksz transition in a homeotropically oriented nematic liquid crystal cell has been considered. The cases of light beams confined in one and two dimensions have been examined. The orientational instability threshold and the jump of a director deviation angle at the transition, as well as their dependences on the transverse size of the incident light beam, were found in the regimes of incident light intensity growth and reduction. Conditions, under which the width of the hysteresis loop is maximal, have been determined. 